\title{
Cucurbit Seed Development and Production
}

Gregory E. Welbaum

ADDITIONAL INDEX WORDs. seed vigor, germination, seed aging, fruit development

Summary. Seed production in the family C ucurbitaceae is more complicated than in dry-seeded grain crops because seeds mature within a moist fruit and are often held at high moisture content for several weeks before seed harvest. M uskmelon (C u cumi smeloL.), a member of this family, was used as a model system to contrast seed development with crops that are dry at maturity. A detailed time course for 'T op M ark' fruit and seed development is presented based on previous studies. In muskmelon fruit, precocious germination is inhibited osmotically by the low water potential of the surrounding fruit tissue. M uskmelon seeds exhibit primary dormancy that affects viability very early in development but has a greater effect on seed vigor and is removed by afterripening during dry storage. 0 smotically distended or fish-mouth seeds are dead seeds that occur in cucurbit seed lots after aging kills the embryo without disrupting the semipermeable endosperm that completely surrounds and protects the embryo. Cucurbit seed crops should be harvested before the onset of fruit senescence to prevent aging of the seeds inside. 0 pen-pollinated cucurbit seed crops are frequently once-over mechanically harvested. Mechanical harvesting combines seeds from many stages of development into a single seed lot, which may adversely affect quality and increase seed to seed variability. $H$ and harvesting cucurbit fruit at the optimal stage of development could improve seed quality in some instances but is more costly and time consuming and would increase production costs.

S

eed maturity in dry-seeded grain crops such as wheat (Triticum aestivum L.) and soybean [Glycinemax (L.) M err.] is punctuated by desiccation (Fig. 1A) (Ackerson, 1984; Barlow et al., 1980). In many crop species, water movement between the maternal plant and fruit is broken at seed maturity, allowing desiccation of the fruit and seed to occur while the plant remains fully hydrated (Adams and Rinne, 1980; Barlow et al., 1980). In species that produce seeds inside a fleshy fruit, such as tomato ( $L$ ycopersi con esculentum M ill.), seeds mature and remain within a relatively moist environment where desiccation is prevented or delayed until after fruit senescence (Fig. 1B). Seed development in fleshy-fruited species has received less research attention than in dry-seeded grain crops. We have investigated seed development in crops that maintain high seed moisture contents to determine the effect on seed quality.

\footnotetext{
Associate professor, D epartment of H orticulture, Virginia Tech, Blacksburg, VA 24061-0327; email: welbaum@vt.edu.

The assistance of I-M o Fu to create Figs. 1 and 3 and M el O luoch to create Figs. 5-6 is greatly appreciated. M ention of a trademark, proprietary product or vendor does not constitute a guarantee or warranty of the product by Virginia T ech or the Virginia C ooperative Extension Service and does not imply its approval to the exclusion of other products or vendors that may also be suitable. The cost of publishing this paper was defrayed in part by the payment of page charges. U nder postal regulations, this paper therefore must behereby marked advertisement solely to indicate this fact.
} 

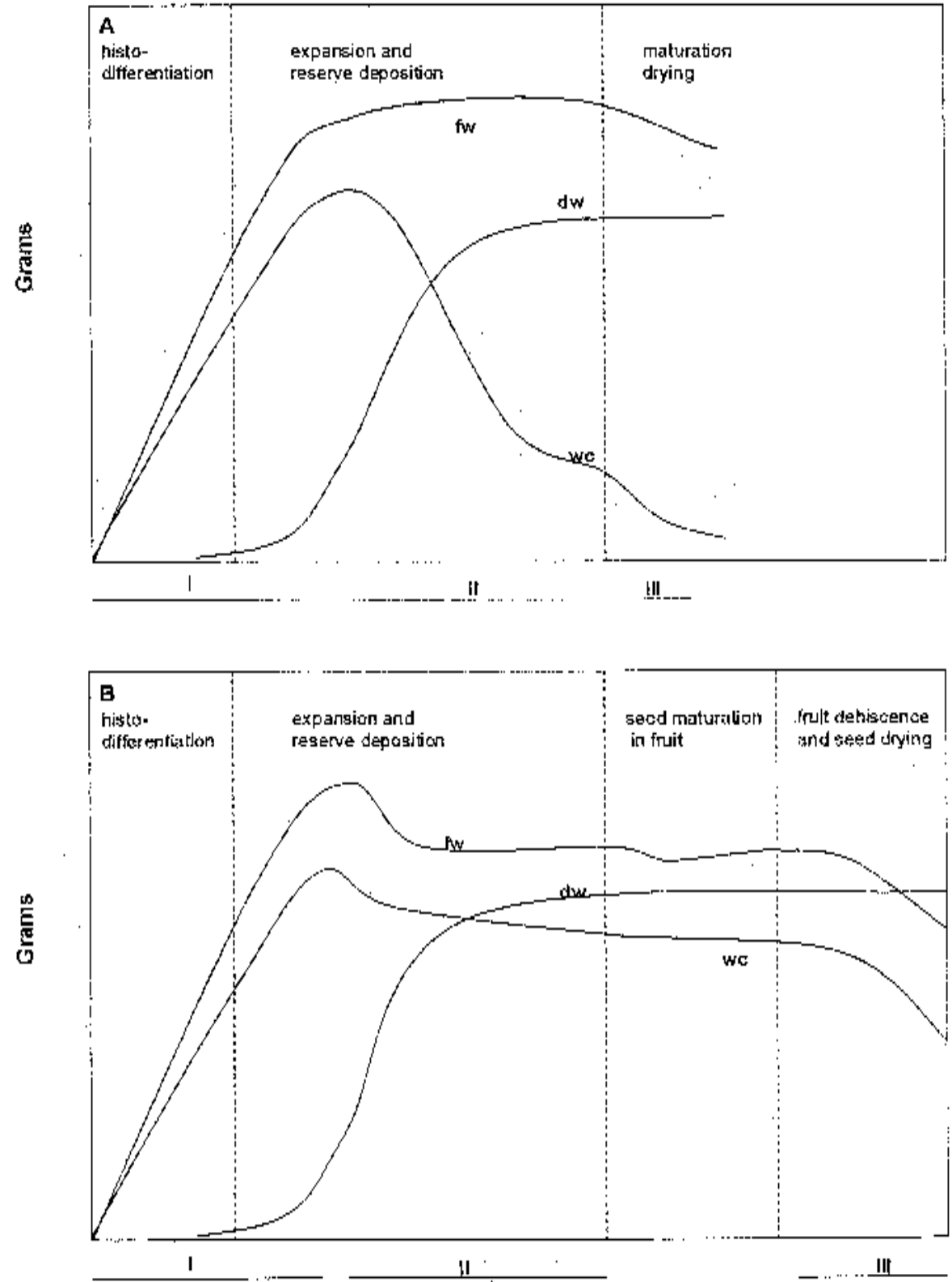

Seed Development (days)

Fig. 1. A relative comparison of seed fresh weight (fw), dry weight (dw), and water content (wc) changes during development for dry-seeded grain crops whose development is punctuated by dryness (A), and crops that develop in flesh fruit like most members of the family C ucurbitaceae (B). Three major phases in seed development are compared: I, rapid gain in fresh weigh because of cell division and early expansion, II, rapid dry weight accumulation driven by cell enlargement, III, loss of fresh weight during drying. Figures contrast relative differences in seed weight for developing wet- and dry-seeded crops based on previous reports in the literature; $28.4 \mathrm{~g}=1 \mathrm{oz}$.
Cucurbit (from the family Cucurbitaceae) seeds remain hydrated inside developing fruit well after maximum dry weight accumulation is obtained (Welbaum and Bradford, 1988). This raises interesting questions about how precociousgermination is prevented and when seed harvest should occur for best quality. M uskmelon provides a good model system for the study of seed development in fleshy-fruited horticultural cropsbecauseits seeds remain near full hydration for weeks after the accumulation of maximum seed dry weight and edible fruit maturity (Fig. 1B) (Welbaum and Bradford, 1988). Cucurbit seedsgrown for propagation have significant economic value in the U .S., and $C$ alifornia is the leading producer. In a recent year, California alone produced almost 7,285 ha (18,000 acres) of cucurbit seeds valued in excess of $\$ 25$ million (U niversity of California, 1992). In this paper, I will review cucurbit seed development with special emphasis on muskmelon seed and fruit.

M uskmelon embryos develop the ability to germinate sequentially well before the accumulation of maximum dry weight which occurs roughly $35 \mathrm{~d}$ after anthesis (DAA) for the cultivar Top M ark. I nitially, developing seeds cannot germinate if removed from the fruit and incubated on water. $\mathrm{H}$ owever, as early as 15 D AA, some embryo tissue growth is observed if testa and endosperm tissues are removed and isolated embryosare placed in the presence of water (Fig. 2A). For example, from 15 to 18 DAA, the cotyledons of isolated immature muskmelon embryos expanded and produced chlorophyll when incubated on blotter paper saturated with water at $25^{\circ} \mathrm{C}\left(77^{\circ} \mathrm{F}\right)$. N o other embryo tissues grew when incubated under similar conditions at thisstage of development (Fig. 2A). At $\approx 20$ D AA, hypocotyls elongated and cotyledons expanded, but root and shoot meristems were not competent to grow when isolated embryos were incubated under favorable conditions (Fig. $2 B$ ). At 25 to $30 \mathrm{DAA}$, roughly $40 \%$ of epicotyls and roots from isolated embryos grew, while the remaining $60 \%$ showed only cotyledon and hypocotyl expansion (Welbaum and Bradford, 1989). By 35 D AA, thetime of mass maturity (maximum dry weight accumulation), all embryonic tissues grew and normal seedlings developed but only when the testa and endosperm were removed. The germination percentage of intact seeds was $<50 \%$ at mass maturity (Fig. 3). G reater than $95 \%$ viability was not obtained by newly 

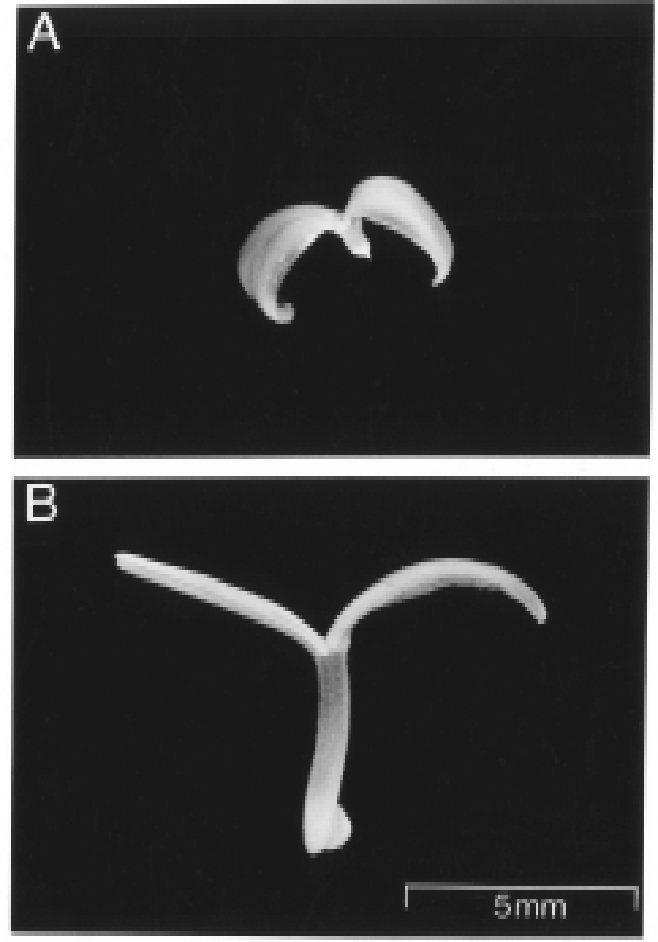

Fig. 2. The growth and development of immature 'T op Mark' muskmelon embryos after isolation from the seed and incubation in water for two weeks at $25^{\circ} \mathrm{C}\left(77^{\circ} \mathrm{F}\right)$. (A) At 15 D AA, cotyledons were the only embryo tissue capable of growth. G rowth occurred when the seed coats and endosperm envelope were removed and the embryos were incubated in water (scale identical to that in panel B). (B) At 20 DAA, in addition to cotyledon growth, hypocotyl growth was also possible in isolated embryos, although the embryonic axis was not yet capable of growth; $25.4 \mathrm{~mm}$ $=1$ inch.

harvested muskmelon seeds until 45 DAA (Fig. 3). G rowth of immatureembryosof other species often occurred only after maternal tissues surrounding the embryo were removed (Kermode and Bewley, 1988; Symons et al., 1983). Also, post harvest drying stimulated both the viability and vigor of immature muskmelon seeds (Welbaum and Bradford, 1989).

$M$ aternal tissues surrounding the embryo, e.g., endosperm and testa, apparently help maintain developmental metabolism through a combination of physical barriersto expansive growth and endogenous plant growth substances (Welbaum et al., 1998). The endosperm completely encloses and creates tension on the fully hydrated embryo before germination (Welbaum and Bradford, 1990a; Welbaum et al., 1998). I n other words, additional expansion and water uptake by fully hydrated seeds only occurs after the endosperm envelope is broken (Welbaum and Bradford, 1990a). When the endosperm envelope is ruptured, the tension is released, decreasing embryo water potential and creating a gradient for the water uptake that drives expansive growth of the radicle during the onset of germination (Welbaum et al., 1998). Thissituation isnot analogousto hard-coated legume seeds, because for many cucurbit seeds, the testa and endosperm pass water freely and do not provide a significant barrier to water movement into the embryo. The endosperm and, to a certain extent, the testa provide a significant physical barrier to embryo expansion in much the same way a tire limits the expansion of the inner tube inside (Welbaum et al., 1998). The end osperm ruptures because of enzymatic induced degradation of endosperm tissue adjacent to the radicle.

Endo- $\beta$-D-mannanase is one enzyme putatively responsible for endosperm weakening in a number of species including members of the family Cucurbitaceae (Welbaum et al., 1998). Endo- $\beta$-D-mannanase activity was low in endosperm tissue of immature 25 and 30 DAA seeds removed from the fruit, dried, and rehydrated for $15 \mathrm{~h}$ at $25^{\circ} \mathrm{C}$ (Fig. 4). Activity peaked 45 to 50 DAA as seeds reached maximum germinability (Fig. 4). The resistance of endosperm tissue to radicle penetration, as measured using an Instron $U$ niversal $T$ esting $M$ achine following hydration for $15 \mathrm{~h}$ at $25^{\circ} \mathrm{C}$, increased during seed development (Fig. 5A and B). The turgor pressure of fully hydrated $30 \mathrm{DAA}$ embryonic axistissue measured directly by psychrometry was 0.6 M Pa (6 bars) (Fig. 6). Thisis 0.2 M Pa (2 bars) lower than previously reported for fully mature and germinable 60 DAA seeds, indicating that maximum embryo turgor before germination increased only slightly during development (Fig. 6; Welbaum and Bradford, 1990a). A pparently, the increased enzyme activity and turgor more than compensate for the increased strength of the endosperm tissue allowing viability to increase as the seeds develop (Fig. 3).

M uskmelon seed development is likely under hormonal control as well. Highest concentrations of abscisic acid ( $A B A$ ) in muskmelon seeds were measured by indirect enzyme linked immunosorbant assay (ELISA) $25 \mathrm{DAA}$ at the point in development when isolated embryo tissues grew only when isolated from the surrounding maternal tissues. The highest concentrations of $A B A$ at 25 DAA were measured in the embryonic axis and endosperm tissue, while cotyledons and testae had much lower ABA contents (Welbaum et al., 1995a, 1999). As seeds develo ped the ability to germinate, ABA concentrations fell to very low levels in all tissues after $40 \mathrm{DAA}$, so the development of germinability is well correlated with a decline in endogenous ABA concentrations. Also, im- 


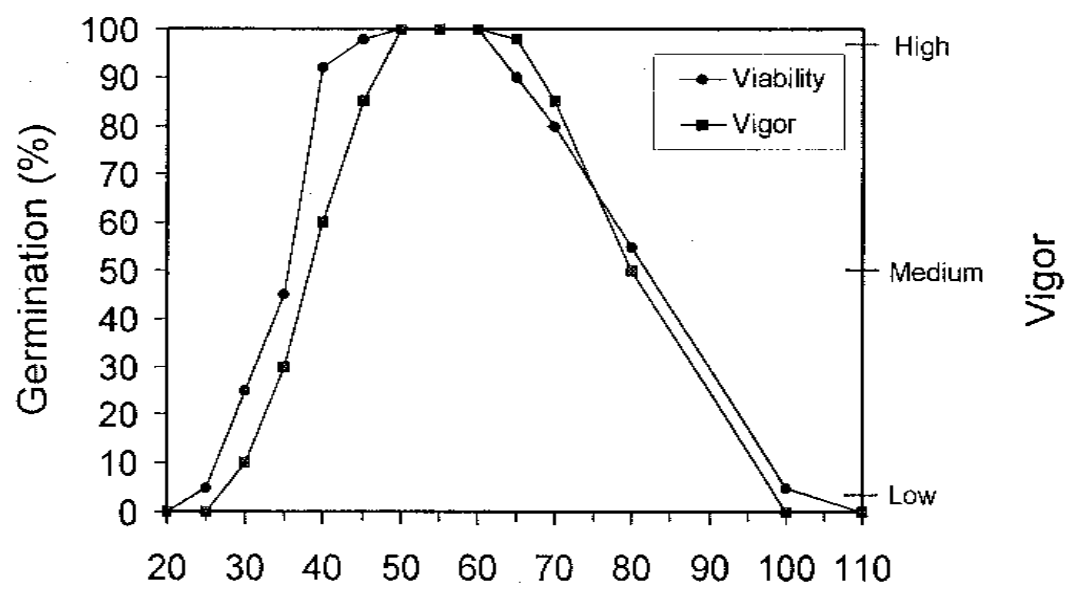

Days After Anthesis

Fig. 3. Comparison of the development and loss of germinability and vigor of 'T op Mark' muskmelon seeds during seed development and senescence from field research in D avis, C alif., and B lacksburg, Va. Viability tests were obtained using standard and modified Association of O fficial Seed Analysts germination tests (AO SA, 1988). Vigor is expressed on a relative scale based on germination rate, 4-d root lengths, and tolerance to water stress and exogenous abscisic acid. D ata were compiled from Welbaum, 1993; Welbaum and Bradford, 1988, 1989; and Welbaum et al., 1990.

mature muskmelon seeds are the most sensitive to exogenous ABA early in development when $A B A$ levels were highest in the tissue (Welbaum et al., 1990). H igher levels of endogenous gibberellic acid-like substances in muskmelon embryos were correlated with superior germination under suboptimal conditions, indicating that gibberellic acid (GA) may play an important role in muskmelon seed germination (Edelstein et al., 1995a). Gibberellic acid levels were not measured in developing seeds in this study.

Post harvest washing in tap water for $3 \mathrm{~h}$ increased vigor as measured by 4-d root lengths during standard germination testing after harvest. (Association of O fficial Seed Analysts, 1988; Welbaum and Bradford, 1989). The increased vigor following post harvest washing was still evident after sto rage for six years under favorable conditions (O luoch and Welbaum, 1996). I t isunknown whether washing increased vigor by leaching inhibitors of seed germination or by some other mechanism. In summary, muskmelon seeds developed the ability to germinate as endogenous $A B A$ decreased, sensitivity to exogenous $A B A$ decreased, turgor increased slightly, mannanase activity increased, and the resistance of the endosperm to penetration also increased.
'T op M ark' M uskmelon seedsreach mass maturity roughly $10 \mathrm{~d}$ before edible fruit maturity (Fig. 7). H owever, precocious seed germination in muskmelon is a relatively rare event even though ABA concentrations are low and the surrounding fruit tissue remains moist during the later stages of development. M uskmelon seeds avoid precocious germination because the accumulation of osmotic solutes, primarily sugars, creates a low water potential inside developing fruit that maintains seed water content below the threshold required for germination (Welbaum et al., 1990). This osmotic inhibition of germination occurs even in the absence of phytohormones because germination is prevented by the low osmotic potential inside the fruit. Precocious germination occurs more frequently in armenian cucumber, which is also Cucumis melo, because these fruit accumulate less sugar and, therefore, have a higher (less negative) fruit osmotic potential (Welbaum, 1993).

The optimum harvest time for cucurbit seed crops varies with the environment and cultivar. For muskmelon seeds, maximum viability and vigor in the field were obtained only for a relatively short period (Fig. 3). U nder typical conditions in the Sacramento Valley of California, seeds remained $100 \%$ viable for roughly $15 \mathrm{~d}$ before a drop in viability was detected (Fig. 3). M aximum vigor in muskmelon seeds, as defined by the rate of germination, developed more slowly than viability (Fig. 3). Vigor remained high at

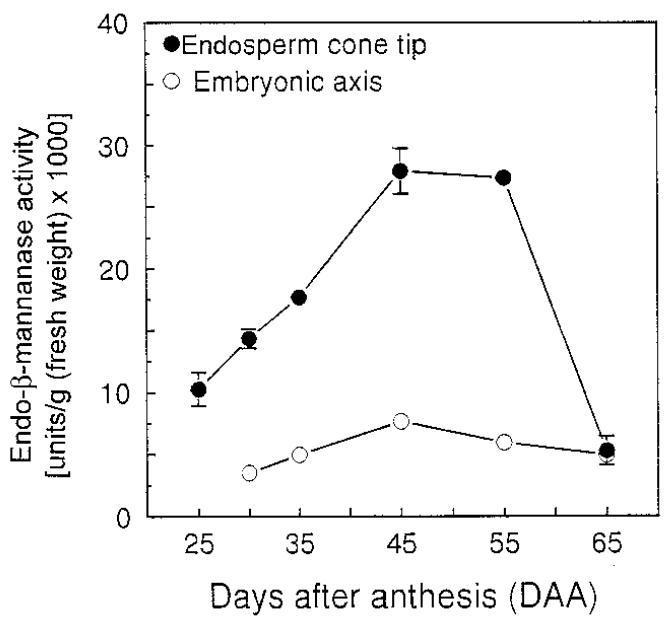

Fig. 4. Endo- $\beta-D$-mannanase activity in 'T op Mark' muskmelon endosperm cone tips at different stages of development determined by a gel diffusion assay (D ownie et al., 1994) after incubation in water for 15 $h$ at $25^{\circ} \mathrm{C}\left(77^{\circ} \mathrm{F}\right)$. E ach point is the mean of four replicates of eight seeds each. E rror bars are \pm SE when larger than the symbols. One unit of enzyme activity is that amount that catalyzes the formation of $1 \mu \mathrm{mol}$ of product per minute. 


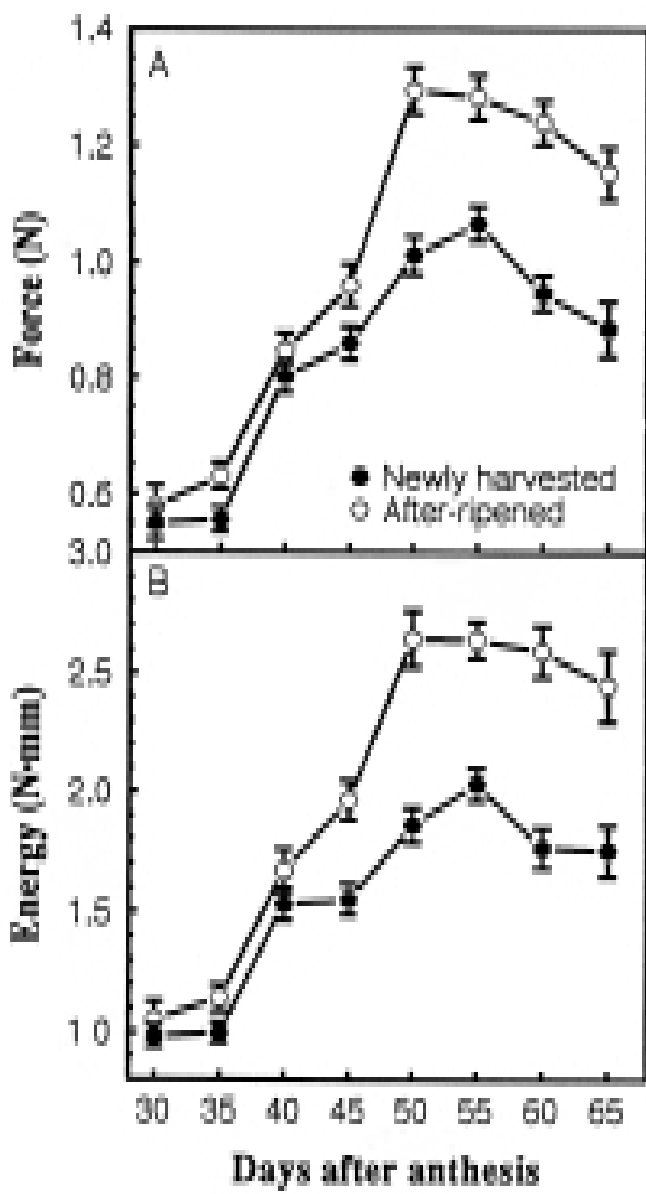

Fig. 5. The force (A) and energy (B) required to penetrate muskmelon seed pieces from eight stages of development following imbibition for $15 \mathrm{~h}$ in water. An Intron Universal testing machine (model 1123; I nstron Engineering C orp., C anton, Mass.) forced a probe, similar in size and shape to the radicle, through the embryonic axis and tissue adjacent to the radicle to estimate resistance to radicle emergence at different stages of development (Welbaum et al., 1995b). M easurements were made immediately following harvest (closed circles) and after five months of dry storage (open circles). E ach point is the mean of three samples of eight seeds each, and error bars are \pm SE when larger than the symbols; $\mathrm{N}=1 \mathrm{~kg} \cdot \mathrm{m}^{-1} \cdot \mathrm{s}^{-2}, \mathrm{~N} \cdot \mathrm{mm}^{-1}=10^{-3} \mathrm{~J}$.

65 D AA as viability began to decline. This is in contrast to traditional wisdom that seed vigor declines more rapidly than viability during deterioration ( $D$ eloucheand Caldwell, 1960). Both viability and vigor fell rapidly with advanced seed deterioration in the field as predicted (Fig. 3).

Seed to seed variation within a lot is a common problem in many crops including the cucurbits. Variation in performance of commercial lots of muskmelon seed has been attributed to combining many individual fruit from different stages of development into a single lot (Oluoch and Welbaum, 1996).
H owever, many other factors besides seed age contribute to seed to seed variation. Seeds from each fruit conceptually form an individual seed lot because the position of the fruit on the plant and the environment affect seed quality (Stephenson, 1992). Therefore, pooling many different fruit to create a lot, even if all were from the same stage of development, increased seed to seed variability. Also, it is likely that not all seeds develop uniformly within a single fruit. In squash (Cucurbita pepo L.), seeds produced from intense pollen competition (more pollen grains per stigma) were more vigorous and exhibited reduced genetic variation than offspring derived from flowers with little pollen competition (Winsor et al., 1987). I n legume fruit, seed position helps to determine the likelihood of abortion, the rate of reserve deposition, and ultimate dry mass (Stephenson, 1992). Seed position inside developing cucurbit fruit likely affects seed development in similar ways.

It is difficult to identify the point of optimal seed quality when harvest should occur. Based on germination rate, low temperature germination, and resistance to controlled deterioration, optimum seed quality occurred when 'T op M ark' fruit are harvested 50 to 55 D AA or $\approx 10 \mathrm{~d}$ past edible maturity (Oluoch and Welbaum, 1996). This is also $\approx 20 \mathrm{~d}$ past seed mass maturity. The development of physiological maturation increases seed vigor and continues after seed mass maturity when seeds are already fully viable. Physiological maturation of seeds proceeds quickly inside maturing and senescing fruit because of the high moisture content and high temperatures inside (Welbaum, 1993). This environment also favors rapid aging if seeds are not harvested and dried to slow the

Fig. 6. W ater potential $(\Psi)$, solute potential $\left(\psi_{\mathrm{s}}\right)$, and pressure potential $\left(\psi_{\mathrm{p}}\right)$ measured for intact $30 \mathrm{~d}$ after anthesis (DAA) 'T op Mark' muskmelon seeds (A), decoated seeds (B), cotyledons (C), and embryonic axes (D) in the hours just before radicle emergence. M easurements of $\Psi$ were made by thermocouple psychrometry on tissues isolated from intact seeds imbibed on water for the times indicated. Solute potential was measured on the same samples after freezing and thawing, and $\psi_{\mathrm{p}}$ was calculated as the difference between $\Psi$ and $\psi_{s}$. Values are means of four to eight replications \pm SE when larger than the symbols. The pressure potential in the embryonic axes of immature 30 DAA seeds just before radicle emergence was $\approx 0.2 \mathrm{MPa}$ ( 2 bars) less than previously reported for mature fully mature and viable 60 DAA axes, indicating that turgor pressure increased only slightly as seeds developed full germinability; $1 \mathrm{MPa}=10$ bars.

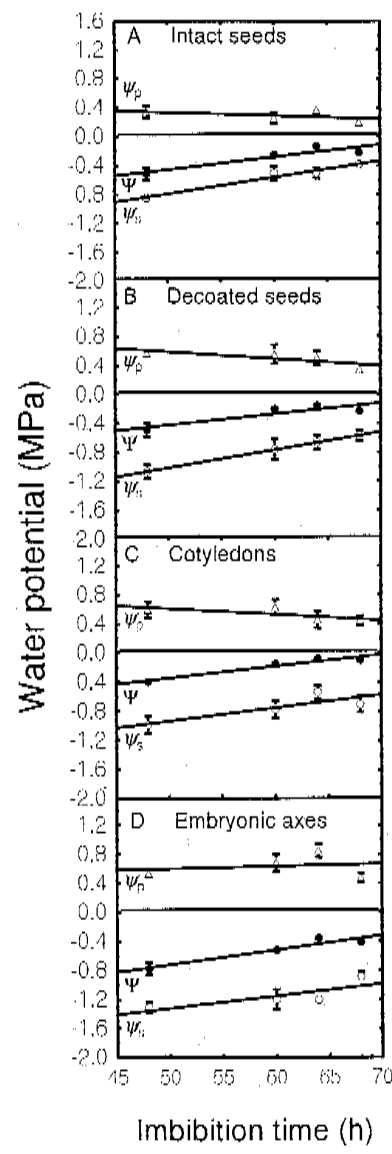


aging process once full physiological maturity has been attained. In the field, the transition from high quality to aged or even dead seeds occurs swiftly over a matter of a few days, particularly at high temperatures (Fig. 3).

'T op M ark' seeds at 50, 55, and 60 D AA germinate rapidly, at low water potentials, at reduced temperatures, and after accelerated aging or long term storage (Oluoch and Welbaum, 1996; Welbaum and Bradford, 1989; Welbaum et al., 1990). In contrast, 65 D AA muskmelon seeds grown under the same conditions showed very high vigor at harvest although a percentage of the seeds had al ready lost viability in the fruit. After long-term storage or accelerated aging, a significant percentage of these seeds had lower viability and vigor compared to less mature seeds (Welbaum and Bradford, 1991a). The additional $5 \mathrm{~d}$ within the fruit caused a fraction of 65 D AA seeds to age beyond peak physiological maturity, reducing seed quality. So delaying muskmelon seed harvest by $5 \mathrm{~d}$ significantly reduced seed quality.

For seeds in dry storage, there is a definite threshold on theaxis of seed longevity defining the border of seed death (Ellis and Roberts, 1981). This hypothesis applies to mature Cucurbit seedsawaiting harvest in thefield aswell. For 'Top M ark' this threshold appears to be roughly $60 \mathrm{DAA}$ under production conditions in California's Sacramento Valley. U nder the adverse conditions that cucurbit seeds are exposed to in production fields, this threshold is reached faster than seedsthat are dried and held in conventional storage. If muskmelon seeds remain inside the fruit until they are released naturally following severefruit decomposition, $\approx 90 \mathrm{DAA}$, a high percentage of the population will likely be dead (Fig. 2, Welbaum, 1993). The rapid aging of muskmelon seeds in senescing fruit isdueto the combined effects of high temperature, low fruit water potential, low oxygen partial pressures, and possibly high carbon dioxide partial pressures. M uskmelon cultivars differ in their sensitivity to anoxia during germination, so certain cultivars may also be more sensitive to the low oxygen environment in decaying fruit than others (E delstein et al., 1995b). Apparently, years of breeding muskmelon fruit for a tough rind that does not quickly decomposealong with high tissuesugar content has impaired the natural reproductive efficiency of this crop. In contrast, armenian cucumber seeds remain viable until the fruit decompose and the seeds are released into the environment (Welbaum, 1993).

A developmental time course for 'Top $M$ ark' seed development and maturation is explained in Fig. 7 based on multiple years of seed production research. The optimum time for seed harvest varies among cultivars, environmental conditionsand must be determined empirically for each production area and culti-

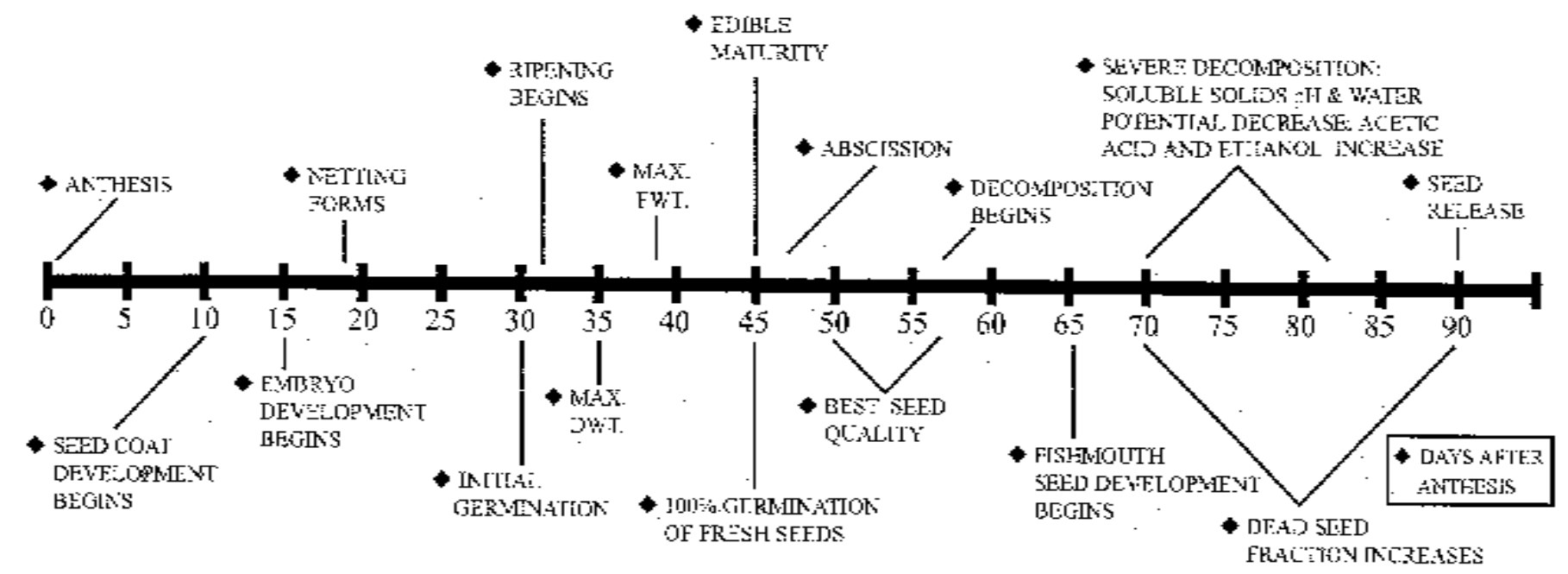

SEED

Fig. 7. Descriptive comparisons of 'T op M ark' muskmelon fruit and seed development from anthesis to fruit decay and seed release. D evel opmental markers are based on data from previous studies of fruit and seed development in $\mathrm{C}$ alifornia and Virginia (Oluoch and Welbaum, 1996; Welbaum, 1993; Welbaum and Bradford, 1988, 1989; and Welbaum et al., 1990). 
var. Seed crop management techniques, that encouragefoliagecover to lower fruit temperatures and allow harvest before severe fruit decomposition occurs, help prevent preharvest losses in seed quality. O nce-over destructive seed harvests contribute to variable cucurbit seed quality because immature and over-mature fruit are combined into a single seed lot. Physiological maturation can also continue while seeds are in the dry state, albeit at a slower rate. In dry seeds, the process is called afterripening and the duration required to achieve maximum vigor varies with cultivar, storage temperature, and moisture conditions. Therefore, muskmelon seed quality may actually improve in dry storage, particularly for seeds harvested between 35 and 50 D AA that have not matured in the fruit. G enerally speaking, the higher the moisture content and temperature, the faster afterripening will occur (Welbaum and Bradford, 1991a). At high temperatures and/ or moisture contents, afterripening can occur in a matter of hours. Under low temperatures and moisture contents, the process may require months (Welbaum and Bradford, 1991a). The physiological mechanisms responsible for afterripening remain poorly understood.

Seed priming, controlled hydration followed by redrying, may substitute for afterripening by making seeds behave as if they were more mature. The water potential inside developing muskmelon fruit is about $-1.3 \mathrm{M} \mathrm{Pa}$ (-13 bars) and approximately the same as an osmotic priming solution (Welbaum and Bradford, 1991b). Apparently, muskmelon seeds are primed in situ during the later stages of development after seed massmaturity. Therefore, seed lots comprised of immature seeds that are not physiologically mature tend to show a greater response to priming than seed lots comprised of older seeds. Priming can effectively improve the quality of seed lots that were harvested prematurely or that have not reached full physiological maturity (Welbaum and Bradford, 1991b).

When seed aging results in extensive soluteleakage, thetestae of muskmelon seeds frequently split apart and appear in side view likean open fish'smouth upon full hydration. These dead seeds are frequently termed fishmouthed or osmotically distended (OD). M uskmelon endosperm is a single suberized cell layer covered with adeposit of callosethat is deposited during development around 30 to 35 DAA (Yim and Bradford, 1998). This tissue was incorrectly identified as perisperm in earlier studies (Singh, 1953; Welbaum and Bradford, 1990b). Additional investigation using electron microscopy revealed that the layer putatively identified as perisperm tissue is actually a deposit of callose on the outer surface of the endosperm tissue (Yim and
B radford, 1998). Fish-mouth seed formation occurs because of the unique semipermeable characteristic of the callose layer associated with endosperm tissue in cucurbit seeds (Welbaum and Bradford, 1990b; Yim and Bradford, 1998). This unique tissue allows water to passfreely but blocksthediffusion of large molecular weight solutes that leak from damaged embryo cells. Thesetrapped solutes attract water resulting in osmotic swelling of the seeds causing the seed coats to split. Cucurbit seed lots frequently contain a high percentage of OD seeds when harvest is delayed and seeds have advanced from physiological maturation into accelerated aging as described above (Fig. 3). N ot all dead seeds show the characteristics of osmotic distention. H owever, all OD seeds are dead.

$O$ verall, cucurbit seed quality in theU .S. is very good. Seed quality could be further improved by applying the results of recent cucurbit seed production and quality research. Seed development in fleshy fruit differs primarily because phase II of seed development is extended over a much longer period of time compared to the more widely studied dryseeded grain crops (Fig. 1). The prolonged hydration may have adverse effects on seed quality under high temperature and other adverse conditions (Welbaum, 1993). Also, many cucurbit seed crops have been bred for longer shelf lifeand, in the case of the melons, higher sugar content which may also negatively affect seed development (Welbaum, 1993). As a consequence, the time of seed harvest in these crops is critical for achieving the best possible seed quality. U nfortunately, there is no simple formula that can be followed for determining the best time to harvest seed crops for all the cucurbits. Research hasshown that muskmelon seed crops should be harvested before the onset of severe fruit senescence to prevent aging of the seeds inside (Fig. 7). Priming can advance the maturity of immature seed lots that were harvested prematurely (Welbaum and Bradford, 1991b). H owever, priming will not restore lost quality to seed lots subjected to preharvest seed aging caused by delayed harvest (Oluoch and Welbaum, 1996). A once-over destructive mechanical harvest is frequently used commercially for open-pollinated cucurbit seed crops but combines seeds from many stages of development into a single lot. Combining seeds from different stages of physiological maturity in this way may adversely affect quality and increase seed to seed variability. $\mathrm{H}$ and harvesting cucurbit fruit at the optimal stage of development could improve seed quality in many cases. $\mathrm{H}$ owever, hand harvesting is a more costly and time-consuming practice that would increase seed production costs. 


\section{Literature cited}

Ackerson, R.C . 1984. Abscisic acid and precocious germination in soybeans. J. Expt. Bot. 35:414-421.

Adams, C.A. and R.W. Rinne. 1980. M oisture content as a controlling factor in seed development and germination. Intl. Rev. Cytol. 68:1-8.

Association of O fficial Seed Analysts. 1988. Rules for testing seeds. J. Seed Technol. 12:1-109.

Barlow, E.W.R., J.W. Lee, R. M unns, and M .G. Smart. 1980. Water relations of developing wheat grain. Austral. J. Plant Physiol. 7:519-525.

D elouche, J.C. and W.P. C aldwell 1960. Seed vigor and vigor tests. Proc. Assn. O fficial Seed Anal. 50:124-129.

Downie, B., H.W.M. H ilhorst, and J.D. Bewley. 1994. A new assay for quantifying endo- $\beta$ - $D$-mannanase activity using congo red dye. Phytochemistry 36:829-835.

Edelstein, M., Y. Ben Tal, M. Wodner, and J. Kigel. 1995a. Role of endogenous gibberellins in germination of melon (Cucumismelo) seeds. Physiol. Plant 95:113119.

Edelstein, M., F. Corbineaux, J. Kigel, and H. N erson. 1995b. Seed coat structure and oxygen availability control low-temperature germination of melon (Cucumis melo) seeds. Physiol. Plant 93:451-456.

Ellis, R.H . and E.H . Roberts. 1981. The quantification of ageing and survival in orthodox seeds. Seed Sci. Technol. 9:373-409.

Kermode, A.R. and J.D. Bewley. 1988. The role of maturation drying in the transition from seed development to germination. $V$. Responses of the immature castor bean embryo to isolation from the whole seed: $A$ comparison with premature desiccation. J. Expt. Bot. 39:487-497.

Oluoch, M.O. and G.E. Welbaum. 1996. Effect of postharvest washing an post-storage priming on viability and vigour of six-year-old muskmelon (Cucumis melo L.) seeds from eight stages of development. Seed Sci. Technol. 24:195-209.

Singh, B. 1953. Studies on the structure and development of seeds of Cucurbitaceae. Phytomorphology 3:224-239.

Stephenson, A.G. 1992. The regulation of maternal investment in plants, p. 152-171. In: C. M arshall and J. Grace (eds.). Fruit and seed production: Aspects of development, environmental physiology and ecology. Cambridge U niv. Press, Cambridge, U.K.

Symons, S.J., R.E. Arnold, M. Black, and J.M. Chapman. 1983. Changes in the growth capacity of the developing wheat embryo. I I Influences of the enveloping tissuesand prematuredrying. J. Expt. Bot. 34:15411550.

U niversity of California Division of Agriculture and $\mathrm{N}$ atural Resources. 1992. Vegetable crops: Acreage and value at a glance. U niv. Calif. Div. Agr. Natural Resources, $O$ akland.

Welbaum, G.E. 1993. Water relations of seed development and germination in muskmelon (C ucumismeloL.).
VIII. Development of osmotically distended seeds. J. Expt. Bot. 44:1245-1252.

Welbaum, G.E. and K.J. Bradford. 1988. Water relations of seed development and germination in muskmelon (Cucumismelo L.). I. Water relations of seed and fruit development. Plant Physiol. 81:406-411.

Welbaum, G.E. and K.J. Bradford. 1989. Water relations of seed development and germination in muskmelon (Cucumis melo L.). II. Development of germinability, vigour, and desiccation tolerance. J. Expt. Bot. 40:1355-1362.

Welbaum, G.E. and K.J. Bradford. 1990a. Water relations of seed development and germination in muskmelon (C ucumismelo L.). V. Water relations of imbibition and germination. Plant Physiol. 92:1046-1052.

Welbaum, G.E. and K.J. Bradford. 1990b. Water relations of seed development and germination in muskmelon (Cucumis melo L.). IV. Characteristics of the perisperm during seed development. Plant Physiol. 92:1038-1045

Welbaum, G.E. and K.J. Bradford. 1991a. Water relations of seed development and germination in muskmelon (C ucumismel oL.). VII I I nfluence of afterripening and ageing on germination responses to temperature and water potential. J. Expt. Bot. 42:1137-1145.

Welbaum, G.E. and K.J. Bradford. 1991b. Water relations of seed development and germination in muskmelon (Cucumismelo L.). VI. I nfluence of priming on germination responses to temperature and water potential during development. J. Expt. Bot. 42:393-399.

Welbaum, G.E., T., Tissaoui, and K.J. Bradford. 1990. Water relations of seed development and germination in muskmelon (Cucumismelo L.). III. Sensitivity of germination to water potential and abscisic acid during development. Plant Physiol. 92:1029-1037.

Welbaum, G.E., E.W. Pavel, D.R. H ill, M .K. Gunatilaka, and R.L. Grayson. 1999. Compartmentation of abscisic acid in developing muskmelon (C ucumismelo L.) seeds. In: Proc. 6th Intl. Wkshp. Seeds. CAB Intl., N ew York.

Welbaum, G.E., D.R. H ill, R.L.G rayson, M. Gunatilaka, and E.W. Pavel. 1995a. L ocalization of ABA in muskmelon seed tissues during development. Program-Abstr. 15th Intl. Conf. Plant Growth Substances. M inneapolis, M inn., 14-18 July 1995 (abstr. 503).

Welbaum, G.E., W.J . M uthui, J.H . Wilson, R.L. Grayson, and R.D. Fell. 1995b. Weakening of muskmelon perisperm envelope tissue during germination. J. Expt. Bot. $46: 391-400$

Welbaum, G.E., K.J. Bradford, K.O. Yim, D.T. Booth, and M.O. O luoch. 1998. Physiological and biochemical processes regulating seed germination. Seed Sci. Res. 8:123-135.

Winsor, J.A., L.E. D avis, and A.G. Stephenson. 1987. The relationship between pollen load and fruit maturation and the effect of pollen load on offspring vigor in Cucurbita pepo. Amer. N at. 129:643-656.

Yim, K.O. and K.J. Bradford. 1998. Callose deposition is responsible for apoplastic semipermeability of the endosperm envelope of muskmelon seeds. Plant Physiol. 118:83-90. 